\title{
Dramatización y comprensión/ interpretación de relatos de ficción: reconstrucción de una experiencia en el tercer ciclo de la escuela fundamental ${ }^{1}$
}

Josette Jolibert

Evelyne Chanques

Françoise Rolland

Sophie Villecourt ${ }^{2}$

\section{Nuestra investigación-acción}

\section{Su formulación}

“¿En qué medida la transposición regular de relatos de ficción en una interpretación dramática puede contribuir a la construcción de competencias de lectores de literatura en el tercer ciclo?"

Este título corresponde a una investigación-acción llevada a cabo durante tres años (desde CE2 hasta CM2) en una misma institución, la Escuela de Práctica Condorcet del IUFM (Instituto Universitario de Formación de Maestros) de Montpellier, con el equipo de maestros del tercer ciclo. ${ }^{3}$

\section{Objetivo de nuestro proyecto}

La constitución y/o la consolidación de competencias lectoras de relatos de ficción en niños del tercer ciclo gracias a la transposición,

1 Este artículo presenta resultados de la investigación-acción realizada por las autoras en la Escuela de Práctica Condorcet del Instituto Universitario de Formación de Maestros de Montpellier (IUfM) e incorpora reflexiones derivadas del taller desarrollado en el Coloquio sobre la Literatura Infantil realizado en Montpellier en abril de 2006. Traducido por María Elvira Rodríguez Luna, grupo de investigación Lenguaje, Identidad y Cultura, Universidad Distrital Francisco José de Caldas, Bogotá, 2008.

2 Josette Jolibert, investigadora en didáctica de la lengua materna, responsable de la investigación. Investigadora principal, jjoliber@club-internet.fr

Equipo del tercer ciclo de la Escuela de Práctica Condorcet del Instituto Universitario de Formación de Maestros (IUFM) de Montpellier en el Sur de Francia, conformado por las maestras-formadoras: Evelyne Chanques (CE2) y Françoise Rolland (см2), y por Sophie Villecourt, maestra formadora y Directora de la Escuela Condorcet.

3 En el sistema educativo de Francia la escuela elemental está organizada en tres ciclos que aproximadamente se corresponden con los grados de la educación preescolar y básica primaria en Colombia: el ciclo I comprende los dos primeros años de la escuela de párvulos y está dirigido a niños entre 2 y 5 años de edad; el ciclo in incluye el último año de la escuela de párvulos (equivalente a transición) y los dos primeros de la escuela elemental obligatoria (Grados $1^{\circ}$ y $2^{\circ}$ de básica primaria en Colombia) y está dirigido a niños entre 6 y 8 años, y el tercer ciclo, comprende los 3 últimos años de la escuela elemental y se conforma por niños cuyas edades están entre 9 y 11 años (Grados 3, 4 y $5^{\circ}$ de básica primaria en el sistema educativo colombiano). A su vez, los ciclos se organizan en cursos. En el presente estudio se hace referencia a los cursos CM1 (intermedio primer año), cE2 (elemental segundo año) y CM2 (intermedio segundo año), incluidos en el tercer ciclo (nota de la traductora). 
reflexiva y sistematizada, de algunas obras de literatura juvenil en representaciones dramáticas.

\section{Nuestra hipótesis de trabajo}

La práctica regular de este tipo de transposición y la reflexión metacognitiva desarrollada paralelamente, inscritas en una estrategia pedagógica de tipo socioconstructivista, constituyen una de las posibles actividades "eficaces" para permitir a todos los estudiantes comprender e interpretar textos literarios que se perciben como "difíciles", "resistentes" y para construirse nuevas competencias como lectores de textos literarios.

\section{¿Qué entendemos por transposición dramática?}

Partimos de la siguiente pregunța general: ¿En qué medida la transposición de un relato de ficción en otro modo de expresión, puede ayudar, por similitud o por contraste, a comprender mejor y a interpretar a la vez el relato preciso que se está transponiendo y su modo de "fabricación"?

Este "otro modo de expresión" habría podido ser una tira cómica, un mimo, el teatro de sombras, etc. Hemos escogido la interpretación dramática, aunque bajo un modo de funcionamiento particular que tenemos que hacer explícito.

Para evitar equívocos, precisemos aquí que no se trata:

- ni de una improvisación dramática con predominio de la expresión de sí y la extrapolación imaginaria,

- ni de la adaptación de un relato de ficción hasta llegar a la representación teatral, - ni de la escritura de un escenario.

(Efectivamente todas estas son actividades que también pueden ser objeto de un tipo de trabajo muy interesante aunque con otros propósitos.)

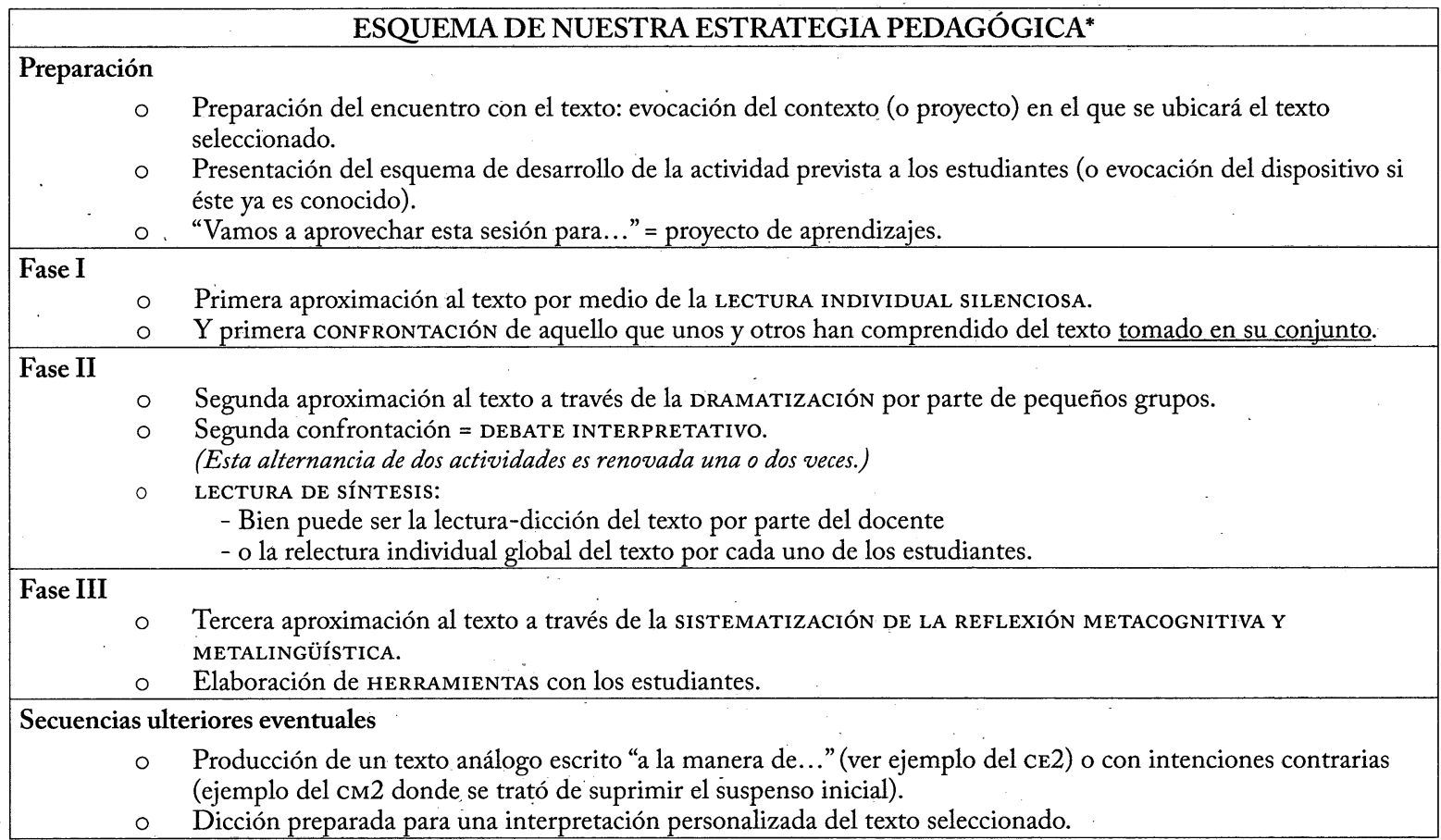

*Nota: la realización precisa de cada una de estas fases depende de cada contexto: clase, texto, momento del año o del ciclo, etc., como se puede observar en los dos ejemplos présentados en el taller.

4 Un texto "resistente" es, según las autoras, "un texto activo, que no se deja conquistar fácilmente por el lector". Por lo tanto no es sinónimo de complicado o complejo (nota de la traductora). 
En nuestro proyecto la regla de juego para pequeños grupos consiste en:

- preparar durante algunos minutos una transposición dramática reflexiva, lo màás fiel posible respecto al relato de ficción seleccionado,

- luego presentarla al resto del curso,

- y por fin confrontarla -desde el punto de vista del relato escrito- con la versión dramatizada de los otros grupos.

Nota: los estudiantes no tienen que aprenderse de memoria el texto correspondiente a su papel sino que usan sus propias palabras para traducir lo que han entendido de la situación.

El objetivo explicito consiste en representar aquello que se ha comprendido del texto, como antesala a un debate interpretativo que le permite al estudiante profundizar aún más en su propia comprensión.

\section{La estrategia pedagógica en la cual se inserta la práctica de la dramatización:}

Este "modelo" constituye uno de los instrumentos que tuvimos que construirnos: se trata de una estrategia pedagógica de tipo socioconstructivista, pensada como un módulo de aprendizaje sistematizado. No se trata pues de una simple técnica, sino que es a la vez un "modelo" en el sentido didáctico del término y un módulo de aprendizaje en el sentido pedagógico.

Hemos tenido que ajustarlo muchas veces para que estimule tanto la participación de cada estudiante de la manera más activa posible en la construcción de su comprensión de un texto, como para lograr una interacción lo más fértil posible con sus pares. La dramatización interviene en la fase II (ver esquema).

\section{Trabajo del taller que realizamos en el coloquio de Montpellier}

\section{La tarea propuesta a los participantes del taller:}

Analizar un corpus de transcripciones de extractos de debates interpretativos entre los estudiantes, los cuales se habían realizado luego de la presentación de la dramatización por parte de los pequeños grupos, que a la vez prepara- ban la etapa siguiente (ver la fase II, del esquema de nuestra estrategia, presentado anteriormente). Para este taller seleccionamos secuencias desarrolladas al comienzo y al final del tercer ciclo, es decir, igualmente al comienzo y al final de nuestra investigación (que se repartió durante los tres años del tercer ciclo):

- en una clase de CE2, en la que se realizaba la primera experiencia de este tipo de dramatización,

- y en una clase de см2, donde los estudiantes habían practicado este tipo de actividad desde su propio CE2, es decir ya durante dos años y medio.

\section{Los textos:}

\section{Es sorprendente ver la facilidad con la que los estudiantes construyen su relación con el texto en su globalidad.}

Los dos relatos de ficción seleccionados fueron escogidos en función de ciertas situaciones particulares que consideramos significativas para la reflexión del taller:

- Como primera experiencia de dramatización en CE2, seleccionamos un cuento tradicional traducido del finlandés, muy estructurado, "Historia de un perro que se buscaba un compañero", reescrito por Natha Caputo.

- Como experiencia final del cm2, elegimos la primera de las diez páginas de una novela corta de ciencia ficción, Impresiones de viaje de Gérard Klein, que consideramos particularmente "resistente" a causa de la ambigüedad en su enunciación.

En el anexo se encuentran los dos textos señalados, el corpus de las transcripciones propuestas para el análisis durante este taller y algunos textos producidos "a la manera de..." por los niños de CE2. 
bate y a descubrir poco a poco la originalidad de esta novela, basada en el suspenso inicial.

En este contexto se afirma de inmediato por parte de los intérpretes una intención de lectura basada en la comprensión del texto. En un primer momento, cada grupo investiga su propia comprensión a través de la preparación de la actuación. En un segundo momento (o al mismo tiempo en los estudiantes entrenados), se manifiesta la preocupación sobre la comprensión por parte de sus espectadores. En el debate que sigue a la primera interpretación dramática, éstos ponen en palabras lo que han sentido intuitivamente: la estructura del relato, de una parte, pero también los sentimientos: el miedo, la cólera, la confianza...

Se nota así que la dramatización favorece la apropiación de la estructura de la bistoria por parte de los estudiantes.

Para la puesta en escena deben identificar las diferentes etapas y la dinámica del texto. De este modo los estudiantes de CE2 pasan por una primera percepción de la "repetición" de los episodios: "Es siempre la misma cosa lo que ocurre. Ellos se encuentran y luego eso no funciona. Es solamente con el hombre que eso funciona [...]" Gracias al debate interpretativo y a una segunda etapa de la dramatización, ellos se encaminarán hacia una representación a través de la cual buscarán hacer sensible "el encadenamiento del miedo", "desde el más pequeño hasta el más grande",en los animales que el perro encuentra, hasta que halle al hombre -que produce miedo pero por el contrario no siente miedo alguno.

Los actores del grupo A de cM2, confrontados a un texto que no presenta una estructura narrativa muy legible de manera inmediata, como sí ocurre con el cuento, toman partido por encontrarle un fin a la historia que desean completar. Durante el debate que sigue a la dramatización, este final es replicado por parte de los estudiantes-espectadores, quienes no reconocen allí su propia interpretación. El docente llamará entonces la atención sobre aquello que el grupo A ha olvidado: si tan sólo se trata del inicio de la novela, ¿es posible que, de entrada, mueran los personajes?

Si bien la dramatización, según nos parece, ha permitido a los estudiantes entrar de lleno en el texto en su globalidad, al reunir los elementos necesarios para permitirles representar una versión completa, esto no les impide en absoluto que hagan una lectura más fina del texto.

Por ejemplo, en CE2 los estudiantes señalaron que el encuentro entre el hombre y el perro se hacía bajo mejores auspicios que los precedentes, debido a que ellos interpretaron las relaciones entre los personajes, se dieron cuenta de que sólo el hombre no respondió a la proposición de compañía por parte del perro con la concesión dubitativa "Bueno...", como los personajes-animales encontrados hasta allí, sino que contestó directamente: "Y ¿por qué no?"

Como lo hemos visto anteriormente, para un grupo de см2 el pasaje del texto de Gérard Klein "Se levantaron a medias, luego sus manos se relajaron y ellos sonrieron", generó un debate respecto a la supervivencia o la muerte de los personajes. Puesto que debían representar la situación, los estudiantes pusieron en juego su poder de inferencia: buscaron una solución (la muerte de los personajes), es decir, una interpretación, aun cuando ésta fuera discutible y ellos supieran que lo era.

De otra parte, el análisis de los debates entre alumnos puso en evidencia la sensibilidad de los estudiantes respecto a la escogencia de la enunciación en estos relatos.

En particular, a través del vaivén entre el texto y la transposición dramática, los estudiantes se interrogan sobre la relación personajes/narrador/autor.

Tanto los ce 2 como los CM2 fueron conducidos a abordar el problema de la existencia y el lugar de un narrador -narrador exteriòr en el cuento, narrador integrado en el texto de ciencia ficción-. Se observa que desde el cE2, los estudiantes se interrogan sobre la función del narrador: ¿se requiere un narrador distinto a los personajes? Si se ha optado por su presencia, interpretar al narrador conduce a los estudiantes a "leer detrás de las palabras": ¿quién dice lo que piensa el perro? " $¿ E 1$ narrador piensa aquello que el perro piensa?”. En realidad en una sesión de lectura clásica es probable que los alumnos no se plantearan tal pregunta.

La atención a la enunciación para extraer el sentido es particularmente manifiesta en la discusión de los CM2 para definir el número de 
personajes (ver el fragmento 3) que un estudiante resumió de la siguiente forma:

Hay tres personajes como mínimo porque se dice "ascendemos, ascendemos", son ya por lo menos dos. Luego aparece "nosotros", eso puede ser yo y otro, ya es obligatorio pues de lo contrario no usarían "nosotros". Más adelante escribió "ellos me miraban y se sonreían", luego hay por lo menos tres personas. Así que están "yo" y los otros dos que sonreían [...]

Para concluir esta parte, podemos decir que los niños, al ser alternativamente actores y espectadores, confrontan de este modo su interpretación del texto, mientras que de forma paralela también construyen sus competencias como lectores de relatos de ficción.

\section{Competencias estratégicas generales ejercidas gracias a la dramatización}

El análisis del corpus también puso de relieve la utilización por los estudiantes de estrategias de lectura más generales tales como el retorno al texto, el empleo de índices para sustentar la argumentación, la formulación de hipótesis o la realización de inferencias. A lo largo de la dramatización $\mathrm{y}$ de los posteriores debates, el texto se mantiene en todo momento como la referencia. Se puede notar cómo los niños vuelven de manera natural al texto para encontrar elementos de ayuda para su comprensión o su interpretación: es gracias a las varias "capas" de lectura sucesivas que los estudiantes se apropian poco a poco del texto para estar en condiciones de hacer una transposición dramática.

Se observa que esta práctica de lectura silenciosa renovada, reforzada con las relecturas parciales necesitadas en las discusiones de los pequeños grupos para llegar a la selección de una interpretación, tiene que ser estimulada en CE2, pero se vuelve espontánea y fácil en CM2.

En los debates, tanto los estudiantes de CE2 como los de CM2 se apoyan en el texto para argumentar y justificar sus puntos de vista, citan pasajes que se han aprendido o que buscan en el mismo texto.

Así, un estudiante de CE2 encuentra un pasaje del cuento y lo lee en voz alta, "Y vio a un hombre que avanzaba hacia él, un leñador que venía de cortar leña", y justifica de esta manera su interpretación sobre la intención "tranquila" del personaje.

Una estudiante de CM2 refuta, por ejemplo, la interpretación del texto según la cual el meteoro habría provocado la explosión del cohete: "Y luego ellos dicen "ruido de cacerolas chocadas». Pero no dicen, «iel cohete ha explotado!»"

Estos múltiples usos de índices textuales manifiestan una relación muy atenta con el texto que permanece en la base de toda la argumentación, sin que ello signifique limitación alguna a la creatividad de su interpretación.

Igualmente la dramatización requiere que los estudiantes formulen hipótesis de sentido.

En CE2, a propósito del encuentro entre el perro y el hombre, un niño informa: "Se pensaba que era porque él quería ver al perro, pero en realidad, eso pasa porque él venía de cortar la leña, en dirección al perro".

Se resalta que en CM2 los lectores intérpretes utilizan con mucha frecuencia el condicional para expresar estas hipótesis: "Yo diría que el cohete habría podido destruirse y que ellos estarían muertos", dice un estudiante de CM2; otro agrega: "Yo, yo diría que se trata de un cohete, no de un platillo volador".

Una vez identificadas las ambigüedades del texto, los niños presentan y confrontan sus interpretaciones, apoyándose en el texto para refutar o validar las hipótesis formuladas.

Entre más nos alejemos de los cuentos tradicionales, evidentemente la comprensión de un relato de ficción más necesita la realización de inferencias por parte de los lectores-actores.

Incluso en un cuento tradicional de estructura repetitiva hemos visto lectores-actores de CE2 inferir que la relación entre el perro y el hombre va a ser mejor ("menos angustiosa" dijeron en un momento no trascrito en el corpus), partiendo del hecho de que el hombre es un leñador que va tranquilamente a cortar leña (en lugar de huir o de tener miedo) y porque expresa una actitud de recibimiento, más abierta, al decir francamente "Y ¿jpor qué no?".

Sin embargo el texto de Gérard Klein es el que requiere por parte del lector la realización de un mayor número de inferencias. Es por esto que 
lo escogimos, dado el efecto literario de suspenso que el autor construyó desde el inicio de la novela. Por esto vemos a los grupos de CM2 buscar, a partir de detalles parsimoniosos o ambiguos del texto, quiénes son los personajes; cuántos son, dónde se encuentran, qué les ocurre, etc.

Nota: la profesora no había planteado ninguna de esas últimas preguntas previamente a la representación dramática (ver extractos 2 y 3). Más tarde (por fuera de nuestro corpus), ella hará descubrir a los estudiantes que esta entrada en la novela funciona como un "incentivo" para el lector y que es necesario continuar la lectura de la novela para poder obtener; poco a poco, las respuestas a estas preguntas que se van desprendiendo del texto.

Finalmente el análisis̀ del corpus permitió poner en evidencia la manera como los estudiantes -particularmente los de CM2- supieron utilizar sus conocimientos previos para ayudarse en la comprensión del texto.

Un ejemplo: "Se trata de un cohete y no de un platillo volador -como los que hemos visto en las películas de dibujos animados-, allí hay una pared en vidrio como ésa", hace énfasis una estudiante para explicar su selección.

Como conclusión a esta parte, podemos decir que las situaciones de dramatización impulsan a los estudiantes a poner en funcionamiento los principales procesos mentales que utiliza estratégicamente un buen lector para comprender mejor e interpretar los textòs.

\section{Los aportes de la dramatización de los textos para los docentes}

La dramatización de ciertos textos "resistentes" nos permitió observar cómo se enfrentan nuestros alumnos a los textos y de qué manera afrontan los problemas que éstos les plantean.

El texto de ciencia ficción, construido sobre la ambigüedad deseada por el autor desde la situación inicial y la imprecisión de los personajes, podía presentar para los estudiantes de $\mathrm{CM} 2$ una dificultad real. Era necesario que la docente tuviera confianza en sus competencias como lectores literarios y pudiera anticipar que ellos sabrían utilizar las competencias adecuadas para entrar en el texto y "sacar algo de esto".

En primer lugar es importante señalar que los estudiantes se lanzaron en la tarea sin dudarlo, en ningún momento renunciaron ante la dificultad del texto. ${ }^{5}$ Su respuesta fue compleja: ellos vivenciaron la ambigüedad del texto aunque sin hacerla explícita.

Dramatizar un texto permite a los niños entrar de inmediato en él, tomar las decisiones respecto a la interpretación para bacerla visible a los otros. No obstante, en el caso de este texto, esta entrada en la acción no permitió hacer explícitas las preferencias literarias del autor (crear un suspenso): por eso, correspondió a la docente hacer el retorno al texto con los estudiantes, haciéndolos reflexionar sobre las intenciones del autor y el papel del lector.

De manera más general uno de los retos para el docente consiste en identificar los obstáculos para la comprensión y la interpretación de los estudiantes y ayudarlos a superarlos.

La dramatización facilita la identificación de las dificultades y el proceso en su conjunto aporta las ayudas necesarias. Como lo hemos visto, en la novela de ciencia ficción se trataba de responder a dos preguntas: ¿Quiénes son los personajes? ¿Qué les ocurre? Al dramatizar, los grupos de niños adoptaron dos estrategias: unos optaron por una interpretación (el meteoro ha chocado al cohete y los personajes murieron), otros permanecieron en la imprecisión (no se sabe quiénes son los personajes). El conflicto resultante creó un terreno favorable para profundizar en su percepción del texto. Fueron los debates posteriores a las dramatizaciones y las preguntas planteadas en ese momento por la docente los que les permitieron volver sobre

\footnotetext{
5 Durante uno de los últimos intercambios, al ser interrogados sobre aquello que habrían hecho solos con este texto, algunos reconocerían que sin la dramatización, sin duda, habrían renunciado a comprenderlo y a tratar de conocer la continuación del relato.
} 
los obstáculos, interrogar la novela para construirse imágenes y confrontar las interpretaciones, es decir, constituirse en lectores plenos.

Por cuanto la actividad de dramatización involucra corporalmente a los intérpretes, pone en tensión al grupo y a los individuos que lo componen.

Es a lo largo del debate que sigue a la dramatización cuando el docente puede hacer emerger las dificultades, permitiendo así a los niños expresar sus puntos de vista y justificar su interpretación: "Cuando se lee un texto uno puede imaginar un poco", afirma un estudiante. E1 maestro es el garante de este derecho y hace respetar la identidad de cada lector, pero siempre solicita una justificación apoyada en el texto.

La actividad de dramatización también permite a los estudiantes abrirse a otras interpretaciones y nutrirse de ellas.

Los estudiantes con dificultades son "andamiados" por el grupo: poco a poco se involucran, participan activamente y también progresan individualmente.

En CE2, una estudiante que no manifiesta grandes facilidades en lectura defiende a su personaje haciendo referencia al texto para justificarlo: " $\mathrm{P}$ Pero no es porque el narrador lo diga todo! ${ }_{i} \mathrm{El}$ perro habla y puede decir sus pensamientos!... ¡No está solamente el narrador!” Ella se involucra motivada por su interpretación dramática del perro. A su manera, participa, lee y relee el texto para encontrar allí los índices que le permiten justificar aquello que su personaje puede o no puede decir.

Otro estudiante, que había "rechazado" su vinculación a la interpretación dramática en la primera preparación de su grupo, termina por "integrarse", mostrando mucha invención frente a la gestualidad del perro.

\footnotetext{
6 La expresión "andamiados" remite al sistema de apoyo que se brinda en la interacción para lograr los desarrollos necesarios frente al dominio de la lengua y la consecución de los fines de la comunicación en los niños, de acuerdo con el Sistema de Apoyo para la Adquisición del lenguaje LASs (Language Acquisition System Support), propuesto por Jerome Bruner. En este caso, los estudiantes que presentan dificultades para la comprensión e interpretación de los textos debido a su complejidad son ayudados por las intervenciones del resto del grupo, las preguntas y orientaciones de la maestra (nota de la traductora).
}

En ce2, la producción individual escrita de un cuento análogo, escrito "de manera parecida a éste" (ver anexo), muestra que los estudiantes de niveles muy diversos son capaces no solamente de retomar aquello que han aprendido, sino que les resulta placentero escribir y leerles a otros lo que han producido. En este caso todos produjeron un cuento.

\section{La dramatización constituye un medio para afinar la comprensión de los textos, particularmente de los textos de ficción, y para estimular la construcción de competencias lectoras. No constituye un fin en sí misma.}

En este proceso, los niños también saben que pueden hacer las réplicas con sus propias palabras puesto que no están obligados a aprenderse los diálogos de memoria. Esta libertad de interpretación es de gran importancia.

Los estudiantes han comprendido intuitivamente, ya desde el CE2, que pueden contar la historia con sus propias palabras, mostrar las situaciones y expresar las emociones y los sentimientos como el miedo, la ira, etc. Ellos se sienten "en confianza", libres para interpretar, teniendo como única referencia el texto literario objeto de escenificación.

Se comprende que, en el marco de esta estrategia pedagógica, el rol del docente es fundamental.

Por una parte, se constituye en un "mediador" que escucha, sugiere, pregunta de nuevo, devuelve a la discusión, propone argumentos e interpretaciones, permitiendo a los niños reflexionar, discutir en los debates interpretativos posteriores a las representaciones dramáticas.

Por otra parte, también ayuda a los estudiantes a forjarse una cultura literaria al hacer que a la vez tomen conciencia y disfruten de las especificidades de un texto literario, de un autor.

Recibe, a cambio, el placer de compartir un gratificante momento de literatura con jóve- 
nes lectores que ya saben expresar su sensibilidad y sacar avante su imaginario.

Más allá de las conclusiones dẹl taller del coloquio, queremos agregar aquí que pudimos experimentar en nuestras clases:

- Que este proceso desarrolla el gusto por compartir, intercambiar, discutir, confrontar las ideas, puntos de vista; que los estudiantes aceptan la crítica, desarrollan una actitud de ayuda mutua, de tolerancia.

- Que el hecho de interpretar para otros y ser alternativamente actores y espectadores moviliza, motiva a los estudiantes y los mantiene atentos y críticos, por cuanto la dramatización confiere una dinámica total a la clase.

- Que nuestros estudiantes explican sus dificultades, se atreven a pedir ayuda cuando sienten la necesidad y buscan ayudar a los otros.

- Que en adelante incorporarán estas actitudes y aprendizajes en las otras disciplinas escolares.

\section{Algunos otros elementos de discusión}

Algunos participantes en el taller se han preguntado "si la interpretación dramática podría bloquear la construcción de imágenes mentales".

Sin duda, en cierta medida una respuesta se encuentra en la diversidad de interpretaciones que los niños expresaron y que no pudimos mostrar en el marco limitado del mencionado taller.

Sin embargo es necesario reconocer que la dramatización de un texto puede presentar riesgos para sus connotaciones imaginarias. Cuando nuestro equipo preparó la secuencia relativa al texto de ciencia ficción, pensamos que la presión por "tener que decidir para poder representar" lo que constituiría la dramatización tenía ante todo como objetivo hacer tomar conciencia a los estudiantes, a partir de la confrontación entre las diferentes interpretaciones posibles, del efecto de expectativa producido sobre el lector, "atrapado" por la ambigüedad de la apertura de este relato. En clase, si un grupo de intérpretes se mantuvo en suspenso, otro, ciertamente por efecto del grupo y para responder a la necesidad de representar, sin dudarlo tomó partido a favor o en contra para hacer explícitas las situaciones y los personajes.

Al descubrir luego (a partir de la lectura de la novela en voz alta realizada por el adulto) que la continuación del relato presenta "a cuentagotas" respuestas precisas pero sorprendentes a estas preguntas iniciales, ciertos estudiantes serán efectivamente "atrapados" por la curiosidad, luego por la compasión hacia los personajes, mientras que otros estarán un poco frustrados al preferir-haber encontrado en el relato de Gérard Klein aquello que ellos habían imaginado. Quedará entonces por proponer la producción de textos yendo en este sentido.

Otros participantes en el taller del coloquio se preguntaron: ¿Cómo se construye la identidad de cada lector en este tipo de dispositivo?

En cuanto hemos experimentado muchas secuencias enteras a partir de una diversidad de textos, en las clases y con estudiantes diferenciados, podemos atestiguar que los niños se encuentran, con la dramatización, comprometidos en situaciones que los estimulan y que los llevan mucho más lejos en su relación con el texto, en su comprensión e interpretación de los textos literarios.

Sin embargo, es necesario decir que es estimulante y estructurante como parte de un módulo de aprendizaje, pero que la dramatización se puede volver una limitante para la creatividad, individual y colectiva, si no se inscribe en un conjunto mucho más diversificado de otras actividades de lectura y producción de literatura juvenil. Otras actividades en las cuales el individuo o el colectivo, según los momentos y los textos, tengan roles diferenciados y donde la relación de cada niño con los textos, a la vez que se apoye en los aprendizajes realizados gracias a la dramatización, sea mucho más autónoma, o incluso llegue a ser totalmente autónoma.

Otra pregunta: ¿Cómo hablar de los progresos de los estudiantes cuando desde la primera experiencia de CE2 se manifiestan competencias tan sorprendentes, y aunque no del todo establecidas, ya por lo menos iniciadas? 
Debemos decir, en primer término, que en las clases también nos sorprendimos desde el comienzo y algunas veces incluso fuimos tomadas desprevenidas por los "hallazgos" de los estudiantes así como por sus producciones. Estos niños ya llegaron al tercer ciclo con una percepción mucho más fina sobre los cuentos de lo que habíamos pensado o de lo que nos mostraban las pruebas de la Evaluación Nacional que toma lugar al inicio del ciclo, es decir de CE2. La situación de dramatización y de debate interpretativo les permitió hacerlo explícito y formularlo.

Si bien este informe del taller ha intentado mostrar que ciertas competencias análogas se manifestaron en la secuencia de CE2 y en la de CM2, tampoco ha perdido de vista que éstas se desarrollaron en contextos y con textos muy distintos. Se podría decir que es gracias a que los niños actuaron del mismo modo a como lo habían hecho con los cuentos (entre otros) en CE2, y con otros relatos en $\mathrm{CMI}$, que pudimos proponerles el relato de Gérard Klein en CM2.

A lo largo de todo el ciclo los progresos de los niños se manifestaron en muchos niveles:

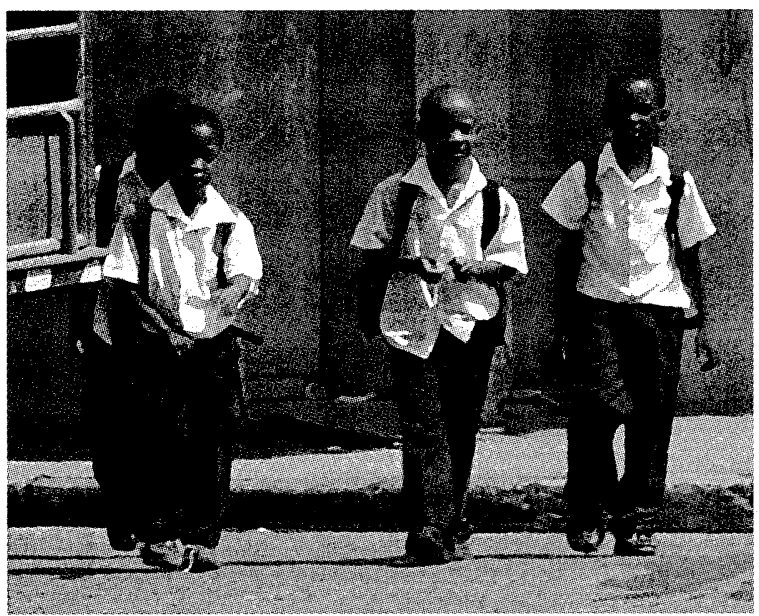

- una comprensión cada vez más fina e interpretaciones más personales de los textos,

- la lectura de textos diversificados, siempre más complejos o pertenecientes a registros poco practicados por ellos (por ejemplo, ellos conocían más la ciencia ficción por los dibujos animados o el cine que a través de los textos literarios),

- una mayor facilidad en su relación con los textos y en la percepción de las situa- ciones, los personajes y los sentimientos, así como en su formulación,

- el hecho de que todos los niños progresaron e incluso algunos lograron "saltos cualitativos" en lectura y en producción de textos que nos alegraron,

- una curiosidad - para algunos, cierta avidez- hacia la lectura que esperamos se pueda prolongar en la escolaridad, etc.

\section{Nuestra conclusión pedagógica general}

Consideramos que se encuentran, en gran parte, confirmadas las hipótesis de trabajo más generales que sustentaban nuestro proyecto:

- Preparar para otros destinatarios (los otros grupos de la clase) la presentación dramatizada de una historia que tan sólo existe bajo la forma de relato escrito es una práctica que obliga a los lectores a comprender y a apreciar de manera mucho más fina la especificidad de la obra de literatura juvenil seleccionada (la trama del relato, los personajes, las situaciones, lo que está en juego, los valores, etc.) y a discutir la interpretación.

- Pasar de un relato (cuento, noticia o novela) a formas de expresión que pongan de manifiesto el discurso directo, obliga al lector a establecer $\mathrm{y}$ a transponer las estructuras narrativas, las modalidades de enunciación, un tratamiento del espacio y del tiempo, los nombres y sus sustitutos, la puntuación, etc., y facilita la comprensión del texto. En síntesis, esta transposición permite a los lectores la construcción de sus competencias tanto lingüisticas como literarias.

- Esta transposición necesita que los lectores-actores anticipen, hagan inferencias, verifiquen hipótesis, identifiquen y combinen índices, seleccionen los elementos significantes, etc. En síntesis, que construyan competencias estratégicas y que éstas se afinen de manera ininterrumpida.

- Este tipo de transposición es una práctica en el curso de la cual los niños se constituyen (de manera individual o colectiva), al 
mismo tiempo y a su vez, en lectores, actores y espectadores criticos. Esta transposición activa las interacciones, los conflictos cognitivos y hace más ricos y profundos los debates interpretativos.

- La comparación entre los dos tipos de situaciones (relato escrito/representación dramática) facilita la toma de conciencia metacognitiva sobre las competencias implementadas y su rol constitutivo en el acto de leer. En este sentido, las actividades de recapitulación metacognitiva, dirigidas por el (la) docente, son imprescindibles para ayudar a los niños a pasar de la utilización de competencias implementadas de manera intuitiva a la elaboración explícita $d e$ berramientas.

\section{Sin embargo:}

- La dramatización de relatos de ficción no es una simple receta lúdica, ocasional, puesto que ésta no logra ni su fuerza ni su eficacia a menos que se incorpore en una estrategia global del tipo que hemos llevado a la práctica.

- La dramatización no encuentra su máxima eficacia a menos que sea practicada regularmente, con textos muy diversos y resulte a la vez familiar y placentera para los niños.

- La dramatización constituye un medio para afinar la comprensión de los textos, particularmente de los textos de ficción, y para estimular la construcción de competencias lectoras. No constituye un fin en sí misma. Debería tener lugar en un abanico muy amplio de interacciones posibles con los textos literarios.

- La práctica de la transposición dramática debe manejarse con precaución (ver discusión anterior) y con particular atención a la escogencia de los textos cuya transformación se propone.

- Existen otras formas de transformación de relatos de ficción que se pueden proponer a los niños según modalidades análogas a las de la dramatización, tales como la mímica o los dibujos animados, por ejemplo.

\section{La dinámica generada en la escuela a partir de esta investigación-acción}

Sería lamentable no hacer mención de aspectos como los siguientes:

- La presencia de todos los miembros del equipo en las sesiones de trabajo (que consistieron, de manera sucesiva, en la preparación, la implementación y la observación de las clases, posteriormente en la evaluación colectiva de las secuencias de trabajo realizadas con los niños) nos permitió analizar cómo funciona la dramatización, lo que allí se pone en juego y la manera como se pone en juego y nos permitió a la vez construir poco a poco una estrategia pedagógica que nos sirva a nosotros de herramienta.

- Este tipo de funcionamiento del equipo ha estimulado un cierto número de rupturas. Rupturas en nuestras prácticas de enseñanza: el hecho de abrir la clase a la mirada de otros. Rupturas en las concepciones de aprendizaje/enseñanza de la lectura y de la literatura. Ruptura con la concepción del maestro que detenta "la" justa interpretación, del "saber" que hay que hacer "adquirir" respecto de "lo que el autor ha querido decir". Ruptura frente al lugar dejado por el maestro a los estudiantes, para permitirles en un primer tiempo "arreglárselas como puedan", espontáneamente, luego ayudarles a superar los obstáculos gracias a las interacciones con sus pares y a la reflexión metacognitiva común que conduce a los aprendizajes.

Ruptura que, igualmente, permite a cada miembro del equipo ocupar su lugar, cualesquiera sean su estatus institucional y sus competencias. La construcción de un pensamiento elaborado colectivamente a lo largo de estos años en el respeto, la escucha del otro, nos ha hecho avanzar a cada uno de nosotros más allá del objeto de la investigación.

En la formación inicial y continua de maestros del IUFM donde nos toca intervenir como formadores, el trabajo realizado en esta investigación-acción puede ser explotado en muchos nive- 
les. La observación fina de la actividad real de los estudiantes, tomados a la vez en su singularidad como en su creatividad en los grupos, permite a los futuros maestros que formemos la construcción de saberes y de estrategias profesionales pertinentes. La reflexión desarrollada por nuestro equipo de trabajo puede aportar claridad didáctica respecto al campo disciplinario enseñado, es decir, el dominio de la práctica del lenguaje.

Al tomar un poco de distancia, podemos pensar que la forma misma de esta investigación, con su propia exigencia y el trabajo en equipo que en ella se desarrolló, resulta un tanto atípica respecto a la vida cotidiana ordinaria de una escuela. Es precisamente esta "atipicidad" en la concepción y en la realización del trabajo lo que ha permitido que la investigación se continúe y que hayamos podido presentarla en equipo, y así "socializar" el fruto de nuestro trabajo, primero en el Coloquio de Aix y ahora en los Encuentros de Montpellier.

\section{Anexos}

\section{A. Documentos de cE2 para el taller del coloquio}

\section{(Clase de Evelyne Chanques)}

\section{El texto:}

\section{"Historia del perro que buscaba un compañero" Cuento finlandés*}

Hace ya mucho, mucho tiempo, tanto que ya he olvidado cuándo, el perro vivía solo en el bosque y no en las casas como ahora.

Un buen día, cansado de vivir así y con el deseo de aburrirse menos, se puso en la búsqueda de un compañero.

Se paseó mucho tiempo sin encontrar a nadie cuando, de pronto, entre dos árboles percibió una liebre que huía.

- ¡Hey!, ¡pequeña liebre! -gritó el perro-. ¡No te salves y escúchame! ¿No te gustaría que viviéramos juntos? Eso sería más divertido...

- Bueno... -dijo la liebre-, ¿por qué no? ¡Intentémoslo!

Escogieron un hermoso rinconcito en el bosque y allí se instalaron. Cuando llegó la noche se acostaron. La pequeña liebre se durmió de inmediato, pero el perro permaneció despierto; había hojas que caían, ramas que traqueaban, pájaros nocturnos que pasaban... y cada vez él ladraba.

La pequeña liebre no podía dormir. Se enfadó y le dijo al perro:

- ¿Cuando vas a dejar por fin de ladrar? Si el lobo te escuchara vendría a devorarnos a los dos...

El perro dejó de ladrar y reflexionó:

- Mi compañera no es valiente... Es miedosa... El lobo tal vez sería mejor, puesto que hace dar miedo a la liebre...

Y el perro, dejando allí a la pequeña liebre, se alejó en búsqueda del lobo. Buscó durante mucho tiempo y de pronto se dio cuenta de que el lobo salía de un soto.

- ¡Hey!, ¡lobo gris, morro puntiagudo! -gritó el perro.- Escúchame, ¿no te gustaría que viviéramos juntos? Eso sería muy divertido...

- Bueno... -dijo el lobo-, ¿por qué no? ¡Intentémoslo!

Cuando llegó la noche se acomodaron para dormir, pero en plena media noche, el perro se despertó por un ruido y se puso a ladrar. Asustado, el lobo se despertó a su vez:

- Cállate, le dijo al perro. Si el oso nos escuchara nos devoraría a los dos...

- ¡Ajá! - pensó el perro-, él no es más valiente que la liebre... Tiene miedo del oso que es ciertamente más fuerte que él.

Y el perro, dejando al lobo allí, se alejó en busca del oso. 
Lo buscó durante mucho tiempo, entre los árboles, los sotos, las rocas. Y he aquí que de repente se encontró nariz a nariz con el oso. Era un gran oso marrón que no tenía por cierto un semblante agradable.

- ¡Hey!, ¡oso marrón, oso con garras, escúchame! ¿No quieres que vivamos juntos? Eso sería muy divertido...

- Bueno..., ¿ ¿por qué no? - gruñó el oso.- Inteǹtémoslo.

Ellos se pasearon todo el día y cuando llegó la noche se acostaron a dormir. Tan pronto el oso se durmió, el perro se puso a ladrar. Al despertarse sobresaltado, el oso tembló de susto.

- Pero cállate, pues -le dijo furioso al perro. - Si el hombre te llegara a escuchar vendría a matarnos...

- Y bien -pensó el perro-, éste no va mejor que los otros... Le teme al hombre...

Y dejando allí al oso que se había vuelto a dormir, el perro partió en búsqueda del hombre.

Pero aunque buscó en el bosque entero, no lo encontraba. Entonces salió a la pradera y se sentó a descansar.

Vio a un hombre que avanzaba hacia él y que venía de cortar leña. Cuando el leñador estuvo bien cerquita, el perro le habló:

- Escúchame, hombre, tú que le produces miedo al oso, que asusta al lobo, que asusta a la liebre... ¿No quieres tomarme como compañero?

- Y ¿por qué no? dijo el hombre. Ven conmigo, y veremos...

Y el hombre se llevó al perro a su casa. En la noche, el hombre se acostó y se durmió. A la media noche, el perro se puso a ladrar. El hombre no se movía y el perro ladraba más fuerte. Entonces el hombre se despertó y le gritó:

- ¡Hey, perro valiente! ¡Come si tienes hambre, bebe si tienes sed, pero déjame dormir tranquilo, por favor!

Él no tiene miedo de nada -pensó el perro-, y sẻ quedó callado.

Comió, bebió y a su vez se durmió.

Y después de todo ese tiempo, el perro ha permanecido como el mejor compañero del hombre.

* Tomado de Natha Caputo, Cuentos de los cuatro vientos, Ed. Nathan.

\section{Transcripción del debate interpretativo}

Repaso de las etapas precedentes (ver esquema de nuestra estrategia pedagógica):

- Los estudiantes (E) formularon hipótesis a partir del título.

- Leyeron silenciosamente el texto.

- Hicieron brevemente la puesta en común de sus impresiones y de lo que comprendieron de la trama de la historia.

- La docente (D) organizó el trabajo de los grupos para la realización de una primera transposición dramática.

El extracto siguiente retranscribe el debate interpretativo que siguió a la representación dramática del primer grupo, el grupo A.

D: Entonces los “espectadores" (es decir, los niños de los otros grupos), ¡tienen la palabra para dar todas sus impresiones!

E: Yo encontré que estaba muy bien.

E: A mí me gustó.
Es: A mí también.

D: ¿Por qué?

E: Yo encontré que ellos escogieron muy bien las palabras.

E: Ellos actuaron bien.

M: ¿Pueden ser un poco más precisos? Recuerden nuestra regla de juego, “ser lo más fiel posible al texto": ¿encuentran que representaron bien el texto? Para ayudarse, que cada uno retome su texto.

(Los estudiantes buscan su texto y se sientan de nuevo en el suelo.)

D: Tomando como referencia el texto que tienen delante de los ojos, y también lo que ustedes mismos prepararon en los otros grupos, ¿qué piensan de la representación del grupo A que acaban de ver? ¿Qué es parecido y qué es diferente entre lo que está escrito y lo que ellos representaron?

(Los estudiantes releen el texto.)

E: Están presentes todos los personajes.

E: Bien, están el perro, luego la liebre, el lobo, el oso... 
E: Y luego el hombre...

$\mathrm{E}$ : Y finalmente el narrador...

D: Volveremos sobre el narrador, veremos si hubo uno en todos los grupos...

$\mathrm{E}: \mathrm{Y}$ pues hay cosas suprimidas.

D: ¿Como cuáles? Por ejemplo, ¿qué les parecería interesante incluir en la representación de los otros grupos venideros?

E: Bueno...

(La docente escribe "Bueno..." en el tablero.)

D: ¿Quien dice "Bueno...”?

E: ¡Todos los animales!

D: ¿'Todos?

E: La liebre, el lobo, el oso.

E: Pero el perro no.

D: ¿Por qué les ha parecido interesante que la liebre, luego el lobo y finalmente el oso digan "Bueno..."?

E: Cada uno dice que quiere intentar pero que no es seguro que permanezcan juntos toda su vida.

D: ¿El hombre dice "Bueno...”?

E: No, él dice directamente "Y ¿por qué no?”

E: Sí, pero... después, se vuelve todo muy complicado si uno busca todos los detallitos.

D: ¿Esos detallitos se encuentran una vez o muchas veces?

E: Muchas veces.

$\mathrm{D}$ : Y entonces ¿jpor qué?

E: Porque siempre pasa lo mismo. Allí se encuentran y luego eso no funciona. Pero ocurre que con el hombre sí funciona...

E: Pero tampoco es igual con el hombre... ellos dicen que, " $y$ vio a un hombre, un hombre que era un leñador que avanzaba hacia él". De hecho, es (el estudiante lee el pasaje del texto en voz alta), "Y vio a un hombre que avanzaba hacia él, un leñador que venía de cortar leña”, pero que no venía hacia el perro porque lo hubiera visto.

E: Entonces... pensábamos que era porque él quería ver al perro pero, en efecto, era porque él cortaba la leña en la misma dirección del perro. Además él no había visto que se trataba de un perro.

D: Y los otros animales, ¿̇cómo encontraron al perró?

(Los estudiantes leen.)
D: Observen cómo la liebre, el lobo, el oso se encuentran con el perro.

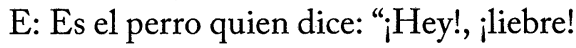
¡Hey!, ¡lobo! ¡Hey!, ¡oso!”, y... (el estudiante busca las palabras.)

D: Sí, él los interpela. Y respecto al hombre ¿no ocurre lo mismo?

E: No, porque el perro sabe que hay un hombre que se acerca, y precisamente es para descansar allá.

E: Pero allí dice "cuando el leñador estuvo muy cerquita el perro habló”.

E: Él no tuvo necesidad de gritar como con los otros.

D: Efectivamente, muy buena observación.

E: Pero yo encuentro... es más una pregunta... ¿El narrador piensa lo que el perro piensa?

E: ¡Ah! ¡Pero claro que sí!

D: ¿Tú quieres responder, G...?

E: ¡Ah! Bueno, ¡sí! No siempre es lo mismo, porque si es el perro quien toma el lugar del narrador o si está en su mente lo que dice el narrador o si es el narrador...

D: F..., desarrolla un poco más tu idea.

E: En nuestro grupo habíamos dicho que era el perro quien decía sus pensamientos, pero susurrando. Nosotros no habíamos desarrollado eso así.

D: Bueno, el narrador debe siempre decir los pensamientos del perro, ¿o sería posible que hiciera hablar al perro y que sea el perro quien diga sus pensamientos?

E: Yo pienso que es el narrador quien más habla pues es quien narra un poco la historia. Pero, está bien pues, por el contrario, el perro no tiene mucho que decir...

E: ¡Pero no es porque el narrador lo diga todo! Pues el perro habla y también puede decir sus pensamientos... ¡ No existe solamente el narrador!

D: ¿YY cómo se ve cuándo habla el perro? ¿Y cómo se sabe que el perro piensa?

E: Él ladra.

D: Bueno, entonces ¿el perro ladra todo el tiempo? Imaginen que no hubiera un narrador... ¿entonces qué pasaría? 
E: Hay que observar cuándo aparecen los guiones.

E: ¡Pero son los mismos guiones cuando el perro habla que cuando el perro piensa!

(La campana de la escuela suena.)

D: Se terminó el tiempo...Lo retomaremos más adelante.

Etapas siguientes:

- Relectura del cuento por parte de cada grupo, con el fin de afinar la interpretación dramática.

- Representación por parte de grupos distintos al grupo A que tienen que tomar en cuenta en su interpretación lo que se acaba de discutir.

- Nuevo debate interpretativo permitiendo poner en palabras aquello que al comienzo solamente eran impresiones: el miedo, la amistad, las relaciones privilegiadas entre el perro y el hombre, etc.

- Reflexión metacognitiva sobre aspectos derivados del cuento y transformación de ésta en herramientas (cuadros, esquemas) en la perspectiva de la producción escrita que seguirá:

- La superestructura de este cuento como repetición.

- Su dinámica basada en el miedo y en el final feliz.

- Producción individual de un cuento análogo "a la manera de" el propuesto.

\section{Escribir un cuento "a la manera de"}

Cuentos producidos (en clase) por estudiantes (de niveles diversos) después de las tres sesiones de dramatización de "La historia de un perro que buscaba un compañero".

Nota: aquí la maestra solamente hizo una "limpieza" ortográfica para facilitar nuestra lectura de los documentos. Naturalmente falta volver a trabajar la compaginación entre párrafos, la coherencia en el sistema de tiempos verbales, precisar la puntuación, continuar la estructuración de la ortografía, etc. Pero tales aspectos corresponden al trabajo normal con el ciclo III que va a comenzar.

\section{- Nina, 8 años}

(Sin título)

Había una vez un perro que un buen día tuvo una pesadilla. De repente tuvo la idea de contarle su pesadilla a alguien y se fue en búsqueda de un jabalí y se la contó pidiéndole que no le dijera a nadie pero cuando llegó la noche éste fue a contarle a todos sus amigos entonces fue a ver al oso y le pidió no contársela a nadie pero el oso se la contó a todos sus amigos, luego el perro fue a contarle al lobo pero él también se la contó a todo el mundo entonces tuvo la idea de contársela al hombre y éste no se la contó a ninguno y es así como el perro es el mejor amigo del hombre.

\section{- Arthur, 8 años .}

(Sin título)

Érase una vez un lobo que iba a la escuela pero que no tenía un amigo.

Un buen día fue a la escuela y preguntó "Quién quiere jugar al lobo encaramado?". Un gran lobo le dijo: “¡Yo!”. Entonces jugó hasta cuando se cansó porque siempre se hacía tocar. Entonces se aburrió de nuevo.

Al día siguiente, preguntó: "Quién quiere jugar a las escondidas?”. Un pequeño lobo dijo: “YYo!" pero al pequeño no le gustó el juego porque no había escondrijo.

Al siguiente día llevó bolas a la escuela y preguntó: "Quién quiere jugar a las bolas?” Uno mediano, como él, le dijo: "Yo" y ellos se divirtieron todo el día y él tuvo un amigo.

\section{- Manon, 8 años}

"La cabra que quería un enamorado"

Érase una vez una cabra que quería un enamorado. Ella se decía que era muy bella. Pero sus padres le repetían todo el tiempo: "mi pequeña cabra, tú eres demasiado joven".

Pero un buen día, la cabra se escapó de su casa para irse en busca de un enamorado. Ella no sabía a dónde ir pero, finalmente, se fue para el bosque y buscó durante largo tiempo.

Pero he aquí que de repente pasa un gallo y la cabra se le acerca y le dice: "Gallo, ¿no quieres ser mi enamorado?". El gallo le responde: “no, 
primero yo soy muy viejo; segundo, estoy casado; tercero, tu no eres una gallina".

Entonces la cabra partió; luego fue donde el lobo quien le dijo: "yo no quiero porque tu eres una cabra, yo soy un lobo y además, uno yo soy casado y dos, tu no eres una loba".

Entonces la cabra partió con la cara triste y fue a casa de un castor. Ella le dijo balbuciendo: "S...señor castor, me desearía como enamorada?” El castor le respondió: “¿Perdón? No, ipero usted está locaj! No, yo no quiero por una simple razón: yo no la amo. ¡Váyase ya!"

Entonces ella partió con el corazón destrozado. Se sentó en una roca pero de inmediato llegó un oso a consolarla y le dijo: "Yo busco una enamorada, ¿no querrías ser la mía ?” La cabra miró al oso y le dijo: “Sí! ¡Sí! yo quiero”.

Entonces se casaron y tuvieron muchos niños.

\section{- Lola, 8 años}

"El conejo que quería las orejas cortas y la cola corta"

De esto hace mucho, mucho tiempo cuando el conejo tenía una enorme cola con unas muy largas orejas. Un buen día, se cansó de vivir así.

Él se paseó durante mucho tiempo y he aquí que de repente vio a un gran león que cuidaba a sus cachorros y le gritó: “¡Hey! Gran león, ¿tu querrías arrancar mi cola y mis orejas? A cambio yo cuidaré tus cachorros."
- ¿Por qué no? ¡Intentémoslo! contento...

- ¿Comenzamos? Preguntó el conejo muy

- De acuerdo, le dijo el león.

Y comenzó a tirar. Asustado, el conejo le dijo: "Tu estás loco? ¡Me vas a matar! Yo parto en busca de alguien más”. Y el conejo, muy enfadado, se fue.

Él buscó durante mucho tiempo y de repente vio a un cocodrilo que cuidada sus huevos y le gritó: "Hey! ¡Cocodrilo! ¿Tú quieres arrancarme mi cola y mis orejas? A cambio yo cuidaré tus huevos".

- ¿Por qué no? Intentémoslo

- ¿Comenzamos? Dijo el conejo muy contento.

- De acuerdo.

Y el cocodrilo lo muerde. Asustado el conejo gritó: “¡Detente! ¡Tienes el deseo de matarme o qué!” El conejo partió, enfadado, muy enfadado.

De repente, él vio a un hombre veterinario y le dijo: "iHombre! Haz algo, yo tengo el deseo de cortar mis orejas y mi cola pero el león y el cocodrilo no pueden hacerlo" El hombre durmió al conejo y le cortó las orejas y la cola.

$\mathrm{Y}$ así es como el conejo es menos salvaje que la liebre.

¡A h! Lo iba a olvidar: y es por eso que los conejos tienen la cola y las orejas más cortas que las liebres.

\section{B. Documentos de cM2 para el taller del coloquio}

\section{(Clase de Françoise Rolland)}

\section{El texto}

"Impresiones de viaje"*

Sabemos que afuera existen la noche y el frío.

Pero no estamos seguros ya de que no tenemos ni una ventana con velo de encaje; ni el ojo giratorio de un periscopio, ni mucho menos una estrecha y larga rendija desde donde impulsar hacia afuera la mirada como un dedo invisible y curioso y navegamos casi tan rápido como la luz, pero no lo sabemos. Esperamos, inmóviles, en la luz amarilla y firme de la electricidad, engastados en nuestra montura de acero, en el seno de la oscuridad y del movimiento del espacio.

- Ascendemos -les digo-, ascendemos al cielo.

Ellos me miran y sonríen.

- Seguro. Y seremos los primeros en volver y en contarlo.

Contar sobre el viaje. Hacemos el más grande viaje jamás soñado por los hombres. Navegamos hacia las estrellas. 
Destrozos de cacerolas chocadas. Un meteoro.

Ellos se levantaron a medias, luego sus manos se relajaron y sonrieron. ¿Van a sonreír así durante las semanas, los meses y los años del más grande de todoș los viajes? [...]

\section{Gérard Klein}

* Tomado de El cometa y otros relatos del cosmos (Dans la comète et autres récits du cosmos), Gallimard, Colección Folio Joven, Ciencia Ficción.

\section{Transcripción de fragmentos de los debates interpretativos}

Dos grupos han presentado su dramatización del texto. La clase entera está reunida para intercambiar sobre las dos representaciones en las cuales los estudiantes participaron como actores o espectadores. Veamos tres fragmentos de la confrontación.

Fragmento n. 01

(¿El cohete se destruyó? $)^{*}$.

D: Ahora, durante un momento corto, vamos a hablar de lo que vimos. Vamos a escuchar a los espectadores y luego vamos a tratar de ver lo que hemos comprendido a fin de hacer enseguida una representación aún mejor. De acuerdo con lo que hemos visto alli -en la primera y en la segunda representación-, ¿̨podemos decir que da buena cuenta del texto? ¿Es coherente? ¿Está conforme al texto?

E: Cuando había un meteoro, éste no destruía el cohete, sino que precisamente lo sacudía y...

E: No.

D: Espera, espera. ¿¿Camille?

E: Yo diría mejor que el cohete habría podido destruirse y que ellos podrían estar muertos porque "ellos sonrieron y sus manos se relajaron". Normalmente éste sería un cohete, entonces en el espacio sería más probable que ellos se murieran con el meteoro. Luego sería necesario que el cohete se aplastara un poco. "Ellos sonrieron y sus manos se relajaron" quiere decir mejor que ellos están muertos. Porque, bueno, estar en el espacio como eso, sin nada. Aquí...

D: ¿El hecho de relajar sus manos y de sonreír significa que todo terminó para ellos? ¿Tú que piensas, Julia?
E: Yo pienso que el meteoro, el meteorito no lo tocó sino que lo chocó. Pues chocar no es destruir completamente. $Y$ luego ellos dicen "cacerolas chocadas" y no dice "el cohete explotó!" En rigor eso podría hacer que nosotros fuéramos sacudidos pero no que el cohete fuera derribado completamente.

D: Entonces eso quiere decir que... o bien el cohete fue chocado, o bien el cohete se rompe. $\mathrm{Y}$ entonces, si es como dice Camille, las personas se murieron dentro del cohete o, según tú lo dices, solamente fueron sacudidas.

E: Sí, pero... no podíamos representar una sacudida. No se sabía hacerlo. Con las cabañas ${ }^{7}$ no se podía mostrar verdaderamente (inaudible) caernos entre nosotros mismos.

E: Pero yo no estoy totalmente de acuerdo con Julia porque cuando uno lee el texto uno puede imaginar un poco; como la cabaña: la hemos podido imaginar un poco.

D: Bueno y entonces ¿qué se imaginaron? ¿El cohete según ustedes fue aplastado?

E: Eh, bueno, nos imaginamos que el meteorito era tanto más grande que el cohete que al chocarlo, eso (inaudible).

E: Nosotros hablamos y estuvimos de acuerdo en que eso había chocado... Eso había chocado al cohete y por eso se habían presentado "ruidos de cacerolas" e inmediatamente después ellos se crispaban pero luego se relajaban y sonreían y entonces hay quien se pregunta si van a sonreír "durante las semanas, los meses y los años" que faltan del gran viaje.

\footnotetext{
7 Nota: para hacer más fácil la ubicación de los participantes en el taller se agregaron los subtítulos entre paréntesis. En ningún caso corresponden a preguntas planteadas de antemano por la docente a sus estudiantes. Se trata en efecto de "cohetes" que los niños construyeron con colchonetas de gimnasia.
} 

grupos?

D: $\mathrm{Y}$ entonces ¿qué les sugerirías a los

E: Que ellos no están muertos. Hubo solamente una sacudida y por eso hubo un ruido de cacerolas pero luego ellos se relajaron y sonrieron.

D: De acuerdo... ¿Escucharon allá los grupos A y B, la proposición de Léa? [...]

Fragmento. .2

(Cohete o platillo volador?)*

E: Yo diría que es un cohete y no un platillo volador porque ellos dicen que es "el primer gran viaje del hombre", alguna cosa como esa, que se trata del primer gran viaje del hombre a las estrellas, entonces se habla del hombre, del humano.

E: ¿¿Y entonces?

E: Entonces eso puede ser que... (muchas voces se superponen.).

D: Entonces ¿cohete?, ¿platillo volador? ¿Lauren?

E: Yo estoy de acuerdo con Jennifer. Se trata de un cohete porque en un platillo volador -en fin, esos que uno ha visto, bueno, en las películas y en los dibujos animados-, hay una pared en vidrio como esa. $\mathrm{Y}$ entonces, se vería que es de noche (inaudible), y que habría una fisura de día, en fin... Se vería porque allá decían "pero no hay ninguna ventana sombreada de encaje y tampoco" (inaudible), pues mire, entonces a mí me parece que en un cohete se ve menos que en un platillo volador.

D: Bueno, entonces... ¿Sí, Cassie?

E: De todos modos para mí no es ni un platillo ni un cohete porque los cohetes que yo he visto en la tele tienen ventanas redondas por donde se puede ver $[\ldots]$

Fragmento.$^{\circ} 3$

(¿Cuántos personajes?)*

D: Pues no se puede saber en relación con el texto exactamente cuántas personas hay. Pero ¿se sabe si hay una o muchas teniendo como referencia el texto? ¿Abdellaq?

E: Muchas.
D: Muchas. ¿Dónde puedes ver que hay muchas personas?

E: Porque ellos se empujan, eso quiere decir que hay muchos.

D: De acuerdo, entonces los personajes que están en la nave a partir del momento en que se presenta la colisión se empujan.

E: También él dice "nosotros ascendemos, ellos se levantaron, nosotros estaremos", él pone el plural todas las veces.

D: "Nosotros ascendemos, nosotros seremos los primeros, nosotros hacemos" están en plural, "Ellos ascendieron" también está en plural, de acuerdo.

E: Tres personas como mínimo porque aparece "nosotros ascendemos, nosotros ascendemos al cielo": se trata por lo menos de dos. Luego aparece un "nosotros", lo que puede ser yo y algún otro, eso ya es obligatorio porque de lo contrario no usaría "nosotros". Después escribió "ellos me miran y ellos sonríen", entonces hay por lo menos tres personas porque están “yo" y las otras dos que sonríen.

E: Entonces hay muchos.

E: Eso es lo mínimo.

D: Por lo menos tres. ¿Y Laurie?

E: Yo no estoy de acuerdo en cuanto a los hombres. Ellos dicen "nosotros hacemos el más grande viaje jamás soñado por los hombres”. Los hombres que están en la Tierra. Y ellos son unos cuantos que están en el espacio.

D: Veamos. [...]

\section{La continuación:}

En efecto todas estas discusiones remiten a la ambigüedad, al efecto de suspenso deseado por el autor. Es necesario leer la continuación de la novela para tener respuestas a todas estas preguntas. Aquello "no precisado" intencionalmente por el autor será analizado con los estudiantes. Luego, ellos producirán textos en los cuales -al contrario del texto de G. Klein- todo se dice, desde la situación inicial; donde el texto deviene puramente descriptivo y explicativo, sin "atrapar" al lector con un suspenso, y podría efectivamente terminar allí... 
Elementos bibliográficos de las obras anteriores publicadas por Josette Jolibert y los equipos que trabajaron con ella:

\section{Publicaciones traducidas al castellano:}

Traducción Dolmen (ahora J. C. Sáez), Santiago de Chile:*

(trad. 1991), Formar niños lectores de textos. textos.

(trad. 1992), Formar niños productores de

(trad. 1995), Formar niños lectores y productores de poemas.

\section{Principales publicaciones directamente en castellano:}

Jolibert, J. e Inostroza, G. (coords.), (1996), Transformar la formacion docente inicial. propuesta en didáctica de lengua materna [obra colectiva de las redes para la Transformación de la Formación Docente de América Latina], auspiciada por la Unesco-orealc, Santiago de Chile, Santillana-unEsco [también disponible en Bogotá, Magisterio, 2002].
Inostroza, G. (colaboración de Jolibert, J.) (1996), Aprender a formar niños lectores y escritores. Talleres de formación docente, Santiago de Chile, Dolmen- unEsco.

Jolibert, J. y Jacob, J. (coords.), (1998), Interrogar y producir textos auténticos. vivencias en el aula, [equipos de investigación-acción de docentes de Valparaíso y Puchuncaví], Santiago de Chile, Dolmen.

Jolibert, J. (2000, septiembre), “'Mejorar o transformar «de veras» la formacion docente? Aspectos críticos y ejes clave", en Lectura $y$ vida, IRA.

\section{La más reciente publicación:}

Jolibert, J. y Sraiki, C. (2006), Des enfants lecteurs et producteurs de textes, París, Hachette.

\section{En curso de traducción al castellano:}

Niños construyendo su poder de leer y escribir textos, Santiago de Chile-Buenos Aires, J. C. Sáez-Manantial. Ó

\footnotetext{
- Ver: www.jcsaezeditor.blogspot.com
} 